\title{
Neonatal rat pups' (Long-Evans DAB) behavioral response to thermal stimuli
}

\author{
DAVID SHURTLEFF \\ University of Massachusetts, Amherst, Massachusetts 01002 \\ and American Museum of Natural History, New York, New York 10024 \\ and \\ ETHEL TOBACH \\ American Museum of Natural History, New York, New York 10024
}

\begin{abstract}
The development of responsiveness to three different substratal temperatures was observed in Long-Evans (DAB) rat pups at Days 1, 2, 3, 6, 8, and 10. From Day 1 to Day 6, pups left the coldest area most quickly and the warm and hot areas equally slowly. They also were most active on the cold areas and least on the warm and hot areas. Duration of time spent on the cold areas was lowest for Days 1 and 2 but not for Day 3. By Day 8, differential responses were no longer statistically significant.
\end{abstract}

Adolph (1957) reported that infant rats move toward the nursing female and attempt to maintain contact with her. He could not rule out, however, that infant rats were responding to stimuli other than warmth. Fowler and Kellogg (1975) found that rats younger than 5 days of age failed to move toward a warm compartment. Rats 6-7 days of age, however, spent considerably more time in the warm area. In a recent study, Bennett (Note 1) observed less movement in rat pups 4-14 days of age when placed at the warm end of a thermal gradient than when placed at a cool end. The present study examined the responsiveness of neonatal rats to various thermal stimuli.

\section{METHOD}

Subjects

Forty-eight Long-Evans rat pups, 24 males and 24 females from eight litters ranging in size from 3 to 8 pups, were used. The litters were born and maintained at the American Museum of Natural History, Department of Animal Behavior.

\section{Maintenance}

The litters were maintained in $30 \times 30 \times 30 \mathrm{~cm}$ two-section solid-bottom cages with cedar shavings. These cages were placed in acoustically buffered environmental chambers $60 \times 31 \times 60 \mathrm{~cm}$ (length by width by height) (Industrial Acoustic Company, Inc.). Purina Rat Chow and water were present ad lib for the lactating female of each litter. Temperature in the chambers ranged from $23^{\circ} \mathrm{C}$ to $28^{\circ} \mathrm{C}$. The room was on a reversed light cycle (dark starting at 7:00 a.m. and light at 7:00 p.m.).

This work was done with the support of the Undergraduate Research Program sponsored by Reader's Digest. For reprints please write Department of Animal Behavior, American Museum of Natural History, Central Park West at 79th Street, New York, New York 10024.

\section{Apparatus}

Temperature of pups and surfaces were measured with a YSI telethermometer (Model 47) with a surface thermister probe $9.5 \mathrm{~mm}$ in diameter.

The floor of the observation apparatus (Figure 1) consisted of a $25 \times 5 \mathrm{~cm}$ piece of Plexiglas that was enclosed by $10-\mathrm{cm}-$ high walls, also made of clear Plexiglas. This surface was marked off in $155 \times 5 \mathrm{~cm}$ squares each maintained at one of the three surface temperatures: hot $\left(39^{\circ} \mathrm{C}\right)$, warm $\left(34^{\circ} \mathrm{C}\right)$, or $\operatorname{cool}\left(26^{\circ} \mathrm{C}\right)$. To obtain the temperature differences, the Plexiglas surface rested $7 \mathrm{~cm}$ above a heating panel (3M, Model EH3582). Five ice cubes, each in an individual plastic container, were in contact with the Plexiglas to keep those areas at $26^{\circ} \mathrm{C}$. Particle board insulation $6 \mathrm{~mm}$ in thickness was placed on the underside of the plastic to insulate it from the heating panel and to provide the five sectors designated as "warm." Those sectors remaining were designated hot, had no insulation on the underside, and received the maximum amount of heat generated from the heating panel below. Thermal variation of the various sectors during any one observation was $\pm 1^{\circ} \mathrm{C}$.

Behavioral patterns and location of rat pups on the surface were recorded with the use of a microswitch keyboard and an Esterline Angus on/off recorder connected to a bank of electromechanical counters. All behavior and location items were read off the counters, yielding frequency and duration.

\section{Procedure}

Pups were observed on Days 1, 2, 3, 6, 8, and 10 (Day 1 = day of birth as noted at 9:00 a.m. each morning). To counterbalance

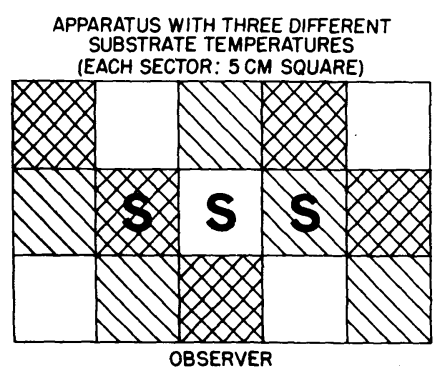

$$
\begin{aligned}
& \square=26^{\circ} \mathrm{C} \\
& \mathrm{D}=34^{\circ} \mathrm{C} \\
& =39^{\circ} \mathrm{C} \\
& S=\text { Starting point }
\end{aligned}
$$

Figure 1. 
the effects of handling the infant rants, half of each litter of five or more pups was assigned to one of two age groups. Each animal was observed only once at a predetermined age. All age groups consisted of four females and four males.

When a litter was being observed, the female was placed in a wire-mesh holding cage with sawdust, food, and water ad lib, and she was kept in a room other than the observation room. All pups were taken from the litter cage and marked dorsally with a coding system with $30 \%$ aqueous gentian violet solution. Each pup was placed in an individual opaque plastic holding cup (9-cm diam) containing home cage shavings. The holding cup was then placed on a $42 \times 69 \mathrm{~cm}$ thermostatically controlled heating tray that maintained a constant surface temperature of $35^{\circ} \mathrm{C}$. The average ventral temperature in the general area of the umbilicus of the rat pup was $34^{\circ} \mathrm{C} \pm 1^{\circ} \mathrm{C}$. All animals were observed between the hours of 10:00 a.m. and 2:00 p.m.

To minimize the effects of a change in olfactory stimulation, the surface of the apparatus was rubbed with home cage sawdust. Each animal was observed by placing it on each of the three substratal temperatures. The sequence was counterbalanced for age, sex, and litter. Each observation from a different starting temperature lasted $2 \mathrm{~min}$. Pups were placed on the appropriate sector in a predetermined fashion, either oriented toward the front of the apparatus or toward the back. In addition to the location of the pup, the following behavior items were recorded: locomotion, pivoting (the posterior end of the pup remained stationary as the pup scrabbled with its front paws, describing a circular motion), twitching, general activity (head activity, either side to side or up and down), and uncoordinated limb movements. Between different temperature observations, rat pups were placed in holding cups on the heating tray for an average of $4 \mathrm{~min}$. During this time, home cage shavings were scattered and rubbed over the surface and removed, and the surface temperature of each sector of the behavioral apparatus was taken and recorded.

\section{RESULTS}

Tables 1, 2, and 3 show that all three measures (latency to move off an area, time spent on substrates of different temperatures, and proportion of activity)

Table 1

Long-Evans (DAB) Rat Pups' Latencies in Moving Off Various Substrates (in Seconds)

\begin{tabular}{|c|c|c|c|c|c|c|c|}
\hline \multirow{3}{*}{$\begin{array}{c}\text { Age } \\
\text { (Days) }\end{array}$} & \multicolumn{6}{|c|}{ Substrate Temperatures } & \multirow[b]{3}{*}{$\mathrm{p}^{*}$} \\
\hline & \multicolumn{2}{|c|}{$26^{\circ} \mathrm{C}$} & \multicolumn{2}{|c|}{$34^{\circ} \mathrm{C}$} & \multicolumn{2}{|c|}{$39^{\circ} \mathrm{C}$} & \\
\hline & Median & Range & Median & Range & Median & Range & \\
\hline 1 & 25.5 & $12.0-120.0$ & 120.0 & & 120.0 & & .01 \\
\hline 2 & 36.0 & $20.0-119.5$ & 120.0 & $50.0-120.0$ & 120.0 & & .01 \\
\hline 3 & 62.0 & $9.5-120.0$ & 120.0 & $99.0-120.0$ & 120.0 & $33.5-120.0$ & .01 \\
\hline 6 & 15.5 & $6.0-120.0$ & 120.0 & $13.5-120.0$ & 120.0 & $22.0-120.0$ & .01 \\
\hline 8 & 19.0 & $6.0-120.0$ & 120.0 & $9.0-120.0$ & 120.0 & $109.0-120.0$ & .07 \\
\hline 10 & 17.5 & $8.0-59.5$ & 31.5 & $4.0-59.5$ & 42.0 & $6.0-120.0$ & n.s. \\
\hline
\end{tabular}

*Friedman two-way ANOVA (Siegel, 1956).

Table 2

Long-Evans (DAB) Rat Pups' Durations of Time Spent on Various Substrates (in Seconds)

\begin{tabular}{|c|c|c|c|c|c|c|c|}
\hline \multirow{3}{*}{$\begin{array}{c}\text { Age } \\
\text { (Days) }\end{array}$} & \multicolumn{6}{|c|}{ Substrate Temperature } & \multirow[b]{3}{*}{ p* } \\
\hline & \multicolumn{2}{|c|}{$26^{\circ} \mathrm{C}$} & \multicolumn{2}{|c|}{$34^{\circ} \mathrm{C}$} & \multicolumn{2}{|c|}{$39^{\circ} \mathrm{C}$} & \\
\hline & Median & Range & Median & Range & Median & Range & \\
\hline 1 & 25.5 & $12.0-120.0$ & 211.0 & $119.5-227.5$ & 120.0 & $119.0-210.0$ & .01 \\
\hline 2 & 36.0 & $20.0-119.5$ & 120.0 & $112.0-149.5$ & 191.0 & $128.5-219.0$ & .01 \\
\hline 3 & 41.5 & $9.5-120.0$ & 120.0 & $40.0-225.0$ & 120.0 & $120.0-182.0$ & n.s. \\
\hline 6 & 61.0 & $6.0-120.0$ & 120.0 & $120.0-163.0$ & 185.0 & $120.0-232.0$ & .01 \\
\hline 8 & 34.0 & $6.0-154.0$ & 125.5 & $58.5-188.5$ & 171.5 & $120.0-232.5$ & n.s. \\
\hline 10 & 98.5 & $33.0-184.0$ & 131.0 & $82.0-248.0$ & 144.0 & $26.5-206.5$ & n.s. \\
\hline
\end{tabular}

*Friedman two-way ANOVA (Siegel, 1956).

Table 3

Long-Evans (DAB) Rat Pups' Proportions of Time Spent in Various Activities (in Seconds)

\begin{tabular}{|c|c|c|c|c|c|c|c|}
\hline \multirow{3}{*}{$\begin{array}{c}\text { Age } \\
\text { (Days) }\end{array}$} & \multicolumn{6}{|c|}{ Substrate Temperature } & \multirow[b]{3}{*}{$\mathrm{p}^{*}$} \\
\hline & \multicolumn{2}{|c|}{$26^{\circ} \mathrm{C}$} & \multicolumn{2}{|c|}{$34^{\circ} \mathrm{C}$} & \multicolumn{2}{|c|}{$39^{\circ} \mathrm{C}$} & \\
\hline & Median & Range & Median & Range & Median & Range & \\
\hline 1 & 50 & $13.0-68$ & 4.1 & $1.0-28$ & 12 & $5.0-25$ & .001 \\
\hline 2 & 65 & $34.0-86$ & 8.6 & $0.0-84$ & 18 & $10.0-31$ & .001 \\
\hline 3 & 62 & $25.0-77$ & 12.0 & $7.1-46$ & 20 & $6.3-44$ & .01 \\
\hline 6 & 40 & $4.0-100$ & 11.0 & $2.5-54$ & 8 & $3.3-30$ & .01 \\
\hline 8 & 65 & $1.3-89$ & 17.0 & 1.9- 96 & 29 & $4.0-66$ & n.s. \\
\hline 10 & 70 & $34.0-95$ & 63.0 & $36.0-100$ & 62 & $21.0-100$ & n.s. \\
\hline
\end{tabular}

*Friedman two-way ANOVA (Siegel, 1956). 
reflected the responsiveness of the rat pup to different temperatures starting from birth. With the exception of duration of time spent on different areas by Day 3 rat pups, the differential responses were evident until Day 8. That thermal responses are preeminent during the earlier stages of development before significant change in locomotor efficiency has been reached is comparable with observations made of rat pups in the nesting situation (Krecek, 1971; Lehrman \& Rosenblatt, 1971).

By Day 8 , the pups are apparently responding to other aspects of the observational procedure and situation.

\section{DISCUSSION}

The demonstration of responsiveness of neonatal rat pups to temperature variations emphasizes the need to consider the integration of this sensory system with others such as olfaction in the socialization process of young rats starting from birth. The striking change at about 6-8 days of age may be related to developmental changes in other physiological systems (Tobach, 1977), which similarly reflect the effects of the reciprocal stimulation of pups and adults during the litter period (Schneirla, 1972).

\section{REFERENCE NOTE}

1. Bennett, B. H. The behavioral development of hypothyroid and hyperthyroid rats. Doctoral dissertation, City University of New York, 1978

\section{REFERENCES}

ADolph, E. F. Ontogeny of physiological regulations in the rat. Quarterly Review of Biology, 1957, 32, 89-137.

FowleR, S. J., \& KELlOGG, C. Ontogeny of thermoregulatory mechanisms in the rat. Journal of Comparative and Physiological Psychology, 1975, 89, 636-647.

Lehrman, D. S., \& Rosenblatt, J. S. The study of behavioral development. In $\mathrm{H}$. Moltz (Ed.), The ontogeny of vertebrate behavior. New York: Academic Press, 1971.

Schneirla, T. C. The concept of development in comparative psychology. In L. R. Aronson, E. Tobach, J. S. Rosenblatt, \& D. S. Lehrman (Eds.), Selected writings of T. C. Schneirla. San Francisco: Freeman, 1972.

Sreger, S. Nonparametric statistics for the behavioral sciences. New York: McGraw-Hill, 1956.

Тов Асн, E. Developmental aspects of chemoception in the Wistar (DAB) rat: Tonic processes. Annals of the New York Academy of Sciences, 1977, 290, 226-269.

(Received for publication October 30, 1978.) 